\title{
Preparación y aceptación de un colutorio casero a base de stevia
}

\author{
Preparation and acceptance of a homemade colutorio with the help of stevia
}

\author{
Gisele Delgado Montoya*
}

http://dx.doi.org/10.21503/CienciayDesarrollo.2010.v11.03

\section{RESUMEN}

El presente trabajo consistió en la preparación de un colutorio casero a base de stevia, para lo cual se utilizaron las tres formas que se consiguen en el mercado: cocimiento de hojas, polvo y líquido. Se probó con los tres y se determinó que la mejor forma para hacerlo de forma casera y de fácil manipulación es la forma líquida; observamos también que bajo esta forma se obtiene una mejor aceptación entre la población.

Palabras clave: stevia, esteviósidos, edulcorante.

\section{ABSTRACT}

This work was the preparation of one homemade mouthwash with stevia, we used three kinds of stevia , leaves, liquid and power, we determined that the most kind of stevia to produce the mouthwash is liquid because is easy to manipulate, we observed that this was the most accepted between the people.

Key words: stevia, esteviosidos, edulcorating

\section{INTRODUCCIÓN}

Los diversos colutorios que se expenden en el mercado tienen dos tipos de edulcorantes: la sacarosa y sacarina; este último especialmente indicado para pacientes diabéticos; pero si bien es cierto que el producto contiene sacarosa, ésta se desdoblará a glucosa y de allí no solo obtendrán energía las bacterias, sino que también cambiará el $\mathrm{pH}$ de la boca, ya que los azúcares disminuyen el $\mathrm{pH}$ de la boca hasta 5,5, lo que permite la desfosforilación y descalcificación de los dientes y los hace más propensos a las caries.

La Stevia rebaudiana Bertoni es una especie sudamericana oriunda del Paraguay, sur de
Brasil y noreste de Argentina. Se la conoce mundialmente como yerba dulce o "ka-ahe-e"(azúcar verde), y las hojas contienen aproximadamente un $42 \%$ de constituyentes solubles en agua, de los cuales se extrae el esteviósido en una porción que varía entre 2 y $22 \% \mathrm{P} / \mathrm{P}$. Pero también posee otros principios endulzantes, como los rebaudósidos A y B, siendo el A, 190 veces más dulce que el B.

El esteviósido en su forma pura es 300 veces más dulce que la sacarosa, y tiene un sabor amargo, pero usado en la concentración adecuada es dulce; los diversos estudios de toxicidad han demostrado que es muy seguro utilizarlo.

*Profesora de Química y Bioquímica de la Escuela Profesional de Estomatología de la Universidad Alas Peruanas, Filial Arequipa. 


\section{MATERIAL Y MÉTODO}

\section{Preparación de colutorios}

Para la preparación del colutorio 1 se empleó lo siguiente:

$\begin{array}{lr}\text { Rp/ } & \\ \text { Tintura de hojas de menta } & 1 \% \\ \text { Tintura de hojas de llantén } & 1 \% \\ \text { Hojas de stevia } & 0,5 \% \\ \text { Alcohol } 70 & 3 \% \\ \text { Agua destilada csp } & 1000 \mathrm{ml}\end{array}$

Se procedió a hervir las hojas de stevia, y una vez fría la decocción, se agregaron los ingredientes uno a uno hasta que se completó los $1000 \mathrm{ml}$.

Para la preparación del colutorio 2 se empleó lo siguiente:

$\begin{array}{lr}\text { Rp/ } & \\ \text { Tintura de hojas de menta } & 1 \% \\ \text { Tintura de hojas de llantén } & 1 \% \\ \text { Stevia en polvo } & 0,2 \% \\ \text { Alcohol } 70 & 3 \% \\ \text { Agua destilada csp } & 1000 \mathrm{ml}\end{array}$

Se colocó en la mitad del agua destilada en primer lugar las tinturas, luego el alcohol; se disolvió el polvo de stevia en $100 \mathrm{ml}$ de agua fría y se agregó a la mezcla, seguidamente se enrazó a $1000 \mathrm{ml}$ con el resto de agua destilada.
Para la preparación del colutorio 3 se empleó lo siguiente:

\section{$\mathrm{Rp} /$}

Tintura de hojas de menta $1 \%$

Tintura de hojas de llantén

$$
1 \%
$$

Stevia en líquido

12 gotas

Alcohol 70

$3 \%$

Agua destilada csp

$1000 \mathrm{ml}$

Se colocó en la mitad del agua destilada las tinturas, luego el alcohol, se disolvió el stevia en líquido en $100 \mathrm{ml}$ de agua fría y se agregó a la mezcla, luego se enrazó a $1000 \mathrm{ml}$ con el resto de agua destilada.

\section{Determinación de la aceptación}

La muestra estuvo compuesta de 200 pacientes mayores de 18 años de la Clínica Odontológica de la Universidad Alas Peruanas Filial Arequipa; se les dio a probar los tres diferentes colutorios y se les pidió la opinión sobre el mejor sabor, calificándolos de la siguiente manera: sabor aceptable, sabor bueno, sabor muy bueno.

\section{RESULTADOS}

Nosotros procesamos los resultados con la prueba estadística Chi cuadrado, la cual nos dio un valor de $\mathrm{p} \leq 1$ con un intervalo de confianza de $95 \%$.

Tabla 1. Calificativo de los colutorios de stevia por los pacientes de la Clínica Estomatológica de la Universidad Alas Peruanas, Filial Arequipa 2009

\begin{tabular}{l|r|r|r|c}
\multicolumn{1}{c|}{ COLUTORIO/ACEPTACIÓN } & ACEPTABLE & BUENO & MUY BUENO & TOTAL \\
\hline Colutorio 1 & 182 & 12 & 6 & 200 \\
Colutorio 2 & 18 & 170 & 12 & 200 \\
\hline Colutorio 3 & 2 & 13 & 185 & 200 \\
\hline TOTAL & 202 & 195 & 203 & 600 \\
\hline
\end{tabular}


Como podemos apreciar en el cuadro 1, el colutorio 1 tuvo un calificativo de aceptable por la mayoría de los participantes; esto se podría deber a que las hojas contienen en su composición algunos compuestos amargos y es un poco más difícil encontrar la dosis exacta; también influye mucho la localidad de donde provengan las hojas de stevia, ya que el porcentaje de esteviósidos depende del lugar donde se cosechó y las características geográficas.

En el mismo cuadro también observamos, que el colutorio 2 recibió un calificativo de bueno, ya que aquí utilizamos el extracto desecado de los esteviósidos, y fue más fácil dosificarlos. El único inconveniente que hubo fue que se debió utilizar una cantidad pequeñísima del mismo, aunque un poco difícil de prepararlo en casa, y se puede correr el riesgo de que si nos pasamos un poco en la dosificación, la solución se agrie.

En el caso del colutorio 3, la mayoría de personas que lo probó determinó que tenía un calificativo de muy bueno; esto podemos determinarlo, tal vez, porque es mucho más fácil dosificar gotas con un simple gotero, ya que se utilizaron solo unas cuantas gotas para la preparación, y las gotas son más uniformes y de fácil contabilidad; esto permite controlar la cantidad mucho mejor y al final obtener un producto superior.

\section{CONCLUSIONES}

Al término del presente trabajo llegamos a las conclusiones siguientes:

1. El colutorio preparado con estevia en líquido fue mejor aceptado por los pacientes encuestados.

2. El esteviósido en forma líquida es mejor dosificado que en polvo o cuando se utilizan las hojas de stevia.

\section{REFERENCIAS BIBLIOGRÁFICAS}

1. Naohiko Sato, President, Stevia Research and Development Center (2003). An Effect of Stevia Extract Liquid on Histamine Metabolism Enzyme in rainbow trout. Faculty of Agriculture, Tohoku University presented in Japanese Society of Fishery Science.

2. Hsieh M., Chan P., Sue Y., Liu J. Liang T., Huang T., Tomlinson B., Chow M., Kao P., Chen Y. (2003)"Efficacy and Tolerability of Oral Stevioside in Stevioside in Patients with Mild Essential Hypertension: a twoyear, Randomized, Placebo-Controlled Study". Clin. Ther., 25,2797-2808

3. Tomita T., Sato N., Arai T., Shiraishi H. Sato M., Takeuchi M., Kamito Y. (1997) "Bactericidal Activity of a Fermented Hot'Water Extract from Stevia rebaudiana Bertoni Towards Enterohemorrhagic Escherichia coli O157:H7 and other Food'Borne Pathogenic Bacteria”. Microbiol. Immunol., 41, 1005-1009.

4. Geuns, J.M.C. (1998) "Stevia rebaudiana Bertoni plants and dried leaves as Novel Food. Final versión" 21.9.1998 with addendum.

5. Evaluation of Certain Food Additives. WHO Food Additives Series 42:119-143, Geneva,1999.

6. Midmore, D. J.; Rank, A. H. (2002). “A new rural industry - Stevia - to replace imported chemical sweeteners". RIRDC Report. Vol. 022. No 02.

7. Mitree-Suttajit (1991). Research on Stevia rebaudiana from the past to the present. Monograph and Conference. Universidad Chiang Mai (Tailandia), Facultad de Medicina, Dpto. de Bioquímica.

8. Kinghorn AD, Soejarto DD. (1985). "Current status of stevioside 
as a sweetening agent for human use". Econ Med Plant Res.

9. Yodyingyuad $\mathrm{V}$,

Bunyawong S. (1991). "Effect of stevioside on growth and reproduction." Hum Reprod.
SITIOS WEB CONSULTADOS

1.<info@steviadulri.com>

2.<tanki@ciudad.com.ar>

3. <www.steviadulri.com>

4. <www.naturessunchine.com> 